\title{
Clinical utility of aqueous humor polymerase chain reaction and serologic testing for suspected infectious uveitis: a single-center retrospective study in South Korea
}

Wungrak Choi, Hyun Goo Kang, Eun Young Choi, Sung Soo Kim, Chan Yun Kim, Hyoung Jun Koh, Sung Chul Lee and Min Kim ${ }^{*}$ (D)

\begin{abstract}
Background: This study aimed to assess and compare the clinical value of aqueous humor polymerase chain reaction (PCR) and serologic tests in patients diagnosed with suspected infectious uveitis.

Methods: In this retrospective observational study, data of 358 patients who were diagnosed with suspected infectious uveitis and who underwent aqueous humor PCR testing were analyzed. PCR and serologic test results were compared with the clinical features.

Results: The rates of initial diagnoses for infectious uveitis were higher with PCR (99 patients, 28\%) compared to those with serologic tests (38 pateints, 11\%). The diagnostic positivity of PCR was 29\% for anterior uveitis, 0\% for intermediate uveitis, 5\% for posterior uveitis, and 30\% for panuveitis. In particular, PCR was useful in confirming the diagnosis of cytomegalovirus and varicella-zoster virus infections and Toxoplasma gondii-associated uveitis. For PCR test, the sensitivity was 0.431 , specificity was 0.985 , and the negative and positive predictive values were 0.506 and 0.980 , respectively. For IgM test, the sensitivity was 0.151 , specificity was 0.970 , and the negative and positive predictive values were 0.403 and 0.895 , respectively.
\end{abstract}

Conclusion: Aqueous humor PCR can be a valuable diagnostic tool for confirming the infectious etiology in patients clinically diagnosed with uveitis. PCR had good predictive and diagnostic value for anterior uveitis and panuveitis compared with that for intermediate and posterior uveitis.

Keywords: Aqueous humor, Infectious uveitis, Plasma, Serologic tests, Polymerase chain reaction, Uveitis

\section{Background}

Uveitis, an important cause of visual impairment in developed countries, affects approximately 200 per 100,000 individuals and accounts for up to $10-35 \%$ of severe visual impairment cases $[1,2]$. Infectious uveitis comprises

\footnotetext{
* Correspondence: minkim76@gmail.com

Institute of Vision Research, Department of Ophthalmology, Yonsei University College of Medicine, 211 Eonju-ro, Gangnam-gu, Seoul 135-720, South Korea
}

approximately $10-20 \%$ of all uveitis cases $[3,4]$. The common pathogens implicated in infectious uveitis are cytomegalovirus (CMV), herpes simplex virus (HSV) types 1 and 2, varicella-zoster virus (VZV), and Toxoplasma gondii [5-7]. Thus, early detection of the causative pathogen and appropriate antimicrobial therapy can prevent visual impairment [1].

C C The Author(s). 2020 Open Access This article is licensed under a Creative Commons Attribution 4.0 International License, which permits use, sharing, adaptation, distribution and reproduction in any medium or format, as long as you give appropriate credit to the original author(s) and the source, provide a link to the Creative Commons licence, and indicate if changes were made. The images or other third party material in this article are included in the article's Creative Commons licence, unless indicated otherwise in a credit line to the material. If material is not included in the article's Creative Commons licence and your intended use is not permitted by statutory regulation or exceeds the permitted use, you will need to obtain permission directly from the copyright holder. To view a copy of this licence, visit http://creativecommons.org/licenses/by/4.0/ The Creative Commons Public Domain Dedication waiver (http://creativecommons.org/publicdomain/zero/1.0/) applies to the data made available in this article, unless otherwise stated in a credit line to the data. 
Several diagnostic tools such as serologic tests, electron or light microscopy, immunoblots, cell cultures, enzyme-linked immunosorbent assay, and GoldmannWitmer coefficient are available; however, the initial diagnosis of infectious uveitis is mainly based on clinical features alone. Occasionally, such diagnoses can be quite challenging because not all patients present with pathognomonic clinical features of uveitis. Moreover, a miotic pupil or media opacity can mask the pathognomonic features, or an overlap in the phenotypic expression caused by different pathogens can limit the diagnostic capability based on clinical examination alone [8]. Incorrect diagnoses could delay the administration of targeted treatment, thereby resulting in visual impairment, use of drugs with undesirable side effects, and the occurrence of uveitis-related complications [9].

Polymerase chain reaction (PCR) is a fast and reliable method, which can identify common pathogens causing uveitis [10]. Aqueous humor PCR can precisely detect small quantities of pathogenic DNA or RNA [11, 12]. The usefulness of PCR in diagnosing infectious uveitis has been established; however, only a few studies have compared the results of PCR with those of plasma serologic tests. This study aimed to assess and compare the clinical value of aqueous humor PCR and serologic tests in patients diagnosed with suspected infectious uveitis.

\section{Methods}

\section{Patient enrollment and study design}

In this retrospective, observational, single-center study, a systematic evaluation of electronic medical records of all enrolled patients was performed. Patients who underwent aqueous humor PCR for clinically diagnosed infectious uveitis between August 2005 and March 2017 at Yonsei University Health System were enrolled in the study. Data collection included the patients' medical history, results of complete ocular examinations (visual acuity, intraocular pressure, and fundus examination), and PCR and serologic test results.

The initial diagnosis was based on clinical presentations and outcomes. Aqueous humor PCR and serologic tests were subsequently performed at the discretion of treating physicians.

\section{Study groups and serologic tests}

The medical records of 358 patients who underwent an aqueous humor PCR test for clinically suspected infectious uveitis were retrospectively reviewed. All patients were divided into the following four groups based on the anatomic location of uveitis: anterior, intermediate, posterior, or panuveitis $[13,14]$. The results of aqueous humor PCR and serologic tests were compared, and the positivity of each method was analyzed. Common pathogens such as CMV, HSV, VZV, Epstein-Barr virus
(EBV), and $T$. gondii were included in the analysis. IgM serologic tests for HSV, VZV, and EBV were performed using the LIAISON ${ }^{\bullet}$ XL Analyzer (DiaSorin S.p.A., Italy) with commercially available kits (LIAISON ${ }^{\bullet}$ HSV-1/2 IgM, LIAISON ${ }^{\bullet}$ VZV IgM, LIAISON ${ }^{\bullet}$ EBV IgM). IgM serologic tests for CMV and T. gondii were performed using Vidas (BioMérieux, Lyon, France) with commercially available kits (VIDAS CMV IgM-bioMérieux, VIDAS Toxo IgM-bioMérieux).

\section{Aqueous humor sampling}

Aqueous fluid sampling was performed during slit lamp examination with topical anesthesia under sterile conditions. A 30-gauge needle was used to extract 0.05-0.1 $\mathrm{mL}$ aqueous humor. The occurrence of aqueous humor sampling-related complications such as intraocular pressure fluctuation and cataract progression was recorded.

\section{PCR}

Real-time PCR was performed within $24 \mathrm{~h}$ of aqueous humor collection according to the manufacturer's instructions. Samples were analyzed for CMV, VZV, HSV, EBV, or T. gondii DNA based on clinical suspicion. The PCR detection threshold (viral copies/mL) was 126 for CMV, 100 for VZV, 154 for HSV, 510 for EBV, and 100 for T. gondii. LightCycler 480 (Roche, Forrenstrasse, Switzerland) was used for real-time PCR. Typically, EBV RQ-PCR was performed using the MagNA Pure 24 System (Roche Diagnostics, Forrenstrasse, Switzerland), Rotor-Gene Q (QIAGEN GmbH, Germany), MagNA Pure 24 Total NA Isolation kit (Roche Diagnostics), and Artus ${ }^{\oplus}$ EBV RG PCR kit (Artus GmbH, Hamburg, Germany). For CMV RQ-PCR, CMV Quantification Real-time PCR kit (BioCore, Seoul Korea) was used. Samples for PCR analysis of HSV, VZV, and T. gondii were outsourced to Seoul Clinic Laboratories (Seoul, Korea).

\section{Statistics}

Data were analyzed using SPSS 22.0 software (IBM Corp., Armonk, NY, USA). Differences among groups were examined using independent t-test or Wilcoxon signed-rank test. $P$-values $<0.05$ were considered statistically significant.

\section{Results}

Of the 358 patients included in this study, 34 had anterior uveitis, 10 had intermediate uveitis, 22 had posterior uveitis, and 292 had panuveitis. The mean age of the participants was $54.05 \pm 16.58$ (range, 13-84) years. The overall diagnostic positivity of PCR and IgM serologic tests for infectious uveitis was 28\% (99/358 patients) and $11 \%$ (38/358 patients), respectively (Table 1 ). The pathogens identified by PCR were 3 cases of HSV, 17 of VZV, 
Table 1 Results of polymerase chain reaction and serologic tests in patients with uveitis

\begin{tabular}{|c|c|c|c|c|c|c|}
\hline & \multirow[t]{2}{*}{ Pathogen } & \multicolumn{5}{|c|}{ Anatomical classification of uveitis } \\
\hline & & $\begin{array}{l}\text { Anterior uveitis } \\
(N=34)\end{array}$ & $\begin{array}{l}\text { Intermediate uveitis } \\
(N=10)\end{array}$ & $\begin{array}{l}\text { Posterior uveitis } \\
(N=22)\end{array}$ & $\begin{array}{l}\text { Panuveitis } \\
(N=292)\end{array}$ & $\begin{array}{l}\text { Total } \\
(N=358)\end{array}$ \\
\hline \multirow[t]{6}{*}{ PCR } & HSV & 2 & 0 & 0 & 1 & 3 \\
\hline & VZV & 1 & 0 & 0 & 16 & 17 \\
\hline & CMV & 7 & 0 & 1 & 59 & 67 \\
\hline & EBV & 0 & 0 & 0 & 2 & 2 \\
\hline & T. gondii & 0 & 0 & 0 & 10 & 10 \\
\hline & Diagnostic positivity & $10 / 34(29 \%)$ & 0/10 (0\%) & $1 / 22(5 \%)$ & 88/292 (30\%) & $99 / 358(28 \%)$ \\
\hline \multirow[t]{6}{*}{ Serum IgM } & HSV & 1 & 1 & 0 & 11 & 13 \\
\hline & VZV & 1 & 0 & 0 & 11 & 12 \\
\hline & CMV & 0 & 0 & 0 & 7 & 7 \\
\hline & EBV & 0 & 0 & 0 & 4 & 4 \\
\hline & T. gondii & 0 & 0 & 0 & 2 & 2 \\
\hline & Diagnostic positivity & 2/34 (6\%) & $1 / 10(10 \%)$ & 0/22 (0\%) & $35 / 292(12 \%)$ & 38/358 (11\%) \\
\hline
\end{tabular}

Results are presented as $N$ or $N$ (\%); $P C R$ polymerase chain reaction, IgM immunoglobulin $\mathrm{M}, H S V$ herpes simplex virus, VZV varicella-zoster virus, CMV cytomegalovirus, EBV Epstein-Barr virus, T. gondii Toxoplasma gondii

67 of CMV, 2 of EBV, and 10 of T. gondii. IgM serologic tests identified 13 cases of HSV, 12 of VZV, 7 of CMV, 4 of EBV, and 2 of $T$. gondii (Table 1).

Ophthalmic findings of HSV-1/HSV-2- and VZV infection included elevated intraocular pressure associated with acute iritis, stellate keratic precipitates throughout the corneal endothelium, large granulomatous keratic precipitates, sectoral or non-sectoral iris transillumination defects, iris pigment epithelium atrophy, decreased corneal sensation, and mydriatic or corectopic pupil at rest. Ophthalmic findings of CMV infection included unilateral (occasionally bilateral) anterior chamber inflammation associated with iris sectoral defects, episodes of ocular hypertension, and diffuse linear or coin-shaped keratic precipitates, occasionally with focal endotheliitis. Ophthalmic findings of Toxoplasma infection were partial- or fullthickness necrotizing retinitis adjacent to an old hyperpigmented chorioretinal scar associated with focal arteritis, overlying vitritis, and anterior chamber cells $[15,16]$.

The sensitivity, specificity, and the negative and positive predictive values for PCR and IgM test were evaluated. For PCR test, the sensitivity was 0.431 , specificity was 0.985 , and the negative and positive predictive values were 0.506 and 0.980 , respectively. For IgM test, the sensitivity was 0.151 , specificity was 0.970 , and the negative and positive predictive values were 0.403 and 0.895 , respectively.

For cases with clinical diagnosis, the PCR positivity values were $0.158,0.630,0.788$, and 0.435 for $\mathrm{HSV}$, VZV, CMV, and T. gondii, respectively, whereas the IgM positivity for clinically diagnosed cases were $0.684,0.444$,
0.082, and 0.087 for HSV, VZV, CMV and T. gondii, respectively (Table 2).

PCR vs. IgM serologic tests for detecting infectious agents in anterior uveitis

Among the 34 patients with anterior uveitis, PCR results were positive in 10 (29\%) patients and IgM serologic test results were positive in $2(6 \%)$ patients. Pathogens detected by PCR were 7 cases of CMV, 2 of HSV, and 1 of VZV. Pathogens detected by IgM serologic tests were 1 case each of HSV and VZV (Table 1).

PCR vs. IgM serologic tests for detecting infectious agents in intermediate uveitis

Among the 10 patients with intermediate uveitis, the diagnostic positivity of PCR and IgM serologic tests was $0 \%$ (0) and 10\% (1 patient), respectively. Although PCR detected no pathogen, IgM serologic tests detected one case of HSV (Table 1).

PCR vs. IgM serologic tests for detecting infectious agents in posterior uveitis

Among the 22 patients with posterior uveitis, PCR results were positive in 1 (5\%) patient, and IgM serologic test results were positive in $0(0 \%)$ patients. PCR identified one case of CMV, whereas IgM serologic tests identified none (Table 1$)$.

PCR vs. IgM serologic tests for detecting infectious agents in panuveitis

Among the 292 patients diagnosed with panuveitis, the diagnostic positivity of PCR and IgM serologic tests was $30 \%$ (88 patients) and 12\% (35 patients), respectively. 
Table 2 Diagnostic parameters of aqueous humor PCR and serum IgM test for clinical diagnosis

\begin{tabular}{lllll}
\hline & Sensitivity & Specificity & Negative predictive value & Positive predictive value \\
\hline $\mathbf{2 a}$ & & & & 0.980 \\
Aqueous PCR & 0.431 & 0.985 & 0.506 & 0.895 \\
Serum IgM & 0.151 & 0.970 & 0.403 & $\mathbf{T . g o n d i i}$ \\
$\mathbf{2 b}$ & & $\mathbf{C M V}$ & 0.435 \\
Clinical diagnosis & HSV & $\mathbf{V Z V}$ & 0.788 & 0.087 \\
PCR positivity & 0.158 & 0.630 & 0.082 & \\
IgM positivity & 0.684 & 0.444 &
\end{tabular}

The sensitivity, specificity, negative and positive predictive values for PCR and IgM test were evaluated. The diagnostic positivity with PCR and IgM was calculated for each clinical diagnosis. PCR polymerase chain reaction, IgM immunoglobulin M, T. gondii Toxoplasma gondii, HSV Herpes simplex virus, VZV Varicella-zoster virus, CMV Cytomegalovirus

PCR identified 59 cases of CMV, 16 of VZV, 10 of $T$. gondii, 2 of EBV, and 1 of HSV. IgM serologic tests identified 11 cases of HSV, 11 of VZV, 7 of CMV, 4 of EBV, and 2 of $T$. gondii (Table 1).

\section{Aqueous humor sampling-related complications}

No significant adverse events associated with aqueous humor sampling were observed during the follow-up period. No significant cataract progression occurred, and no cases of intraocular hypertony or hypotony were observed. No statistically significant differences in intraocular pressure were observed between the groups during the follow-up period (data not shown). Moreover, no patient reported adverse systemic events during the followup period.

\section{Discussion}

This study reports an overall diagnostic positivity of $28 \%$ for PCR compared with $11 \%$ for IgM serologic tests to identify uveitis-associated infectious agents. A goldstandard diagnostic tool to detect infectious uveitis is lacking despite numerous studies. Clinical diagnosis based on medical history and ocular examination remains the widely accepted methodology; however, few supportive diagnostic tools exist that help to confirm the primary clinical diagnosis.

Aqueous humor PCR has been proposed as a possible diagnostic tool in several studies [7, 10, 12, 17, 18]. However, the usefulness of PCR in the diagnosis of infectious uveitis remains controversial. A retrospective study reported a $10 \%$ diagnostic positivity of aqueous humor PCR for diagnosing anterior uveitis [17], whereas another study has reported a diagnostic positivity of $30 \%$ [12]. These diverging results can be attributed to different study designs and the type of uveitis [17, 19]. The geographical region and patient population can also affect study results based on epidemiologic variabilities in the spread of viruses. Furthermore, some institutions perform routine PCR for all patients with uveitis, while others decide on a case-to-case scenario based on clinical suspicion $[17,19]$.

In South Korea, there are some reports on the clinical patterns of uveitis but none on the prevalence of pathogens identified in infectious uveitis cases. In this study, the pathogens detected using either PCR or serologic tests were CMV in 69 (59\%) patients, VZV in 23 (20\%), HSV in 14 (12\%), and T. gondii in 10 (9\%) (Fig. 1). CMV and VZV were the causative pathogens in the majority (79\%) of infectious uveitis cases. These results differ largely with those reported in other studies on nonAsian Caucasian patients in which HSV, VZV, and T. gondii were the most commonly identified pathogens [20-22]. Some geographically proximal countries to South Korea, such as India, Africa, and Japan, have reported HSV, T. gondii, and Mycobacterium tuberculosis as the most commonly detected pathogens in patients with uveitis [22-26].

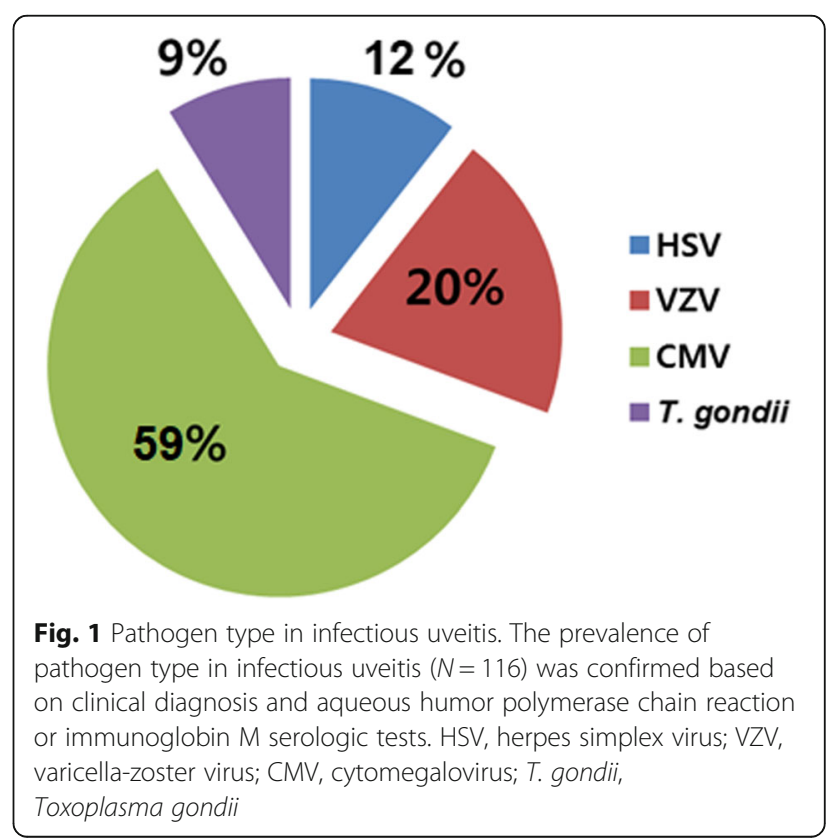


Table 3 Clinical diagnoses for those patients whose PCR and serology testing were both negative

\begin{tabular}{|c|c|c|c|c|c|}
\hline \multirow[t]{2}{*}{ Clinical diagnosis } & \multicolumn{5}{|c|}{ Anatomical classification of uveitis } \\
\hline & $\begin{array}{l}\text { Anterior uveitis } \\
(N=24)\end{array}$ & $\begin{array}{l}\text { Intermediate uveitis } \\
(N=9)\end{array}$ & $\begin{array}{l}\text { Posterior uveitis } \\
(N=21)\end{array}$ & $\begin{array}{l}\text { Panuveitis } \\
(N=184)\end{array}$ & $\begin{array}{l}\text { Total } \\
(N=238)\end{array}$ \\
\hline Herpetic keratitis & 2 & 0 & 0 & 0 & 2 \\
\hline Herpes uveitis & 0 & 0 & 0 & 3 & 3 \\
\hline Zoster ophthalmicus & 2 & 0 & 0 & 2 & 4 \\
\hline Endotheliitis & 5 & 0 & 0 & 0 & 5 \\
\hline CMV retinitis & 0 & 0 & 0 & 16 & 16 \\
\hline T. gondii & 0 & 0 & 3 & 10 & 13 \\
\hline Toxocariasis & 0 & 0 & 2 & 5 & 7 \\
\hline Pseudomonas & 0 & 0 & 0 & 1 & 1 \\
\hline Fungal & 0 & 0 & 0 & 3 & 3 \\
\hline Syphilis & 0 & 0 & 0 & 2 & 2 \\
\hline Tuberculosis & 0 & 0 & 0 & 2 & 2 \\
\hline Endophthalmitis & 0 & 0 & 0 & 24 & 24 \\
\hline Lymphoma & 0 & 0 & 0 & 4 & 4 \\
\hline Acute retinal necrosis & 0 & 0 & 0 & 19 & 19 \\
\hline Unclassified & 15 & 9 & 16 & 93 & 133 \\
\hline
\end{tabular}

Results are presented as $N$; $P C R$ polymerase chain reaction, $H S V$ herpes simplex virus, VZV varicella-zoster virus, CMV cytomegalovirus, $T$. gondii Toxoplasma gondii

In this study, EBV was detected by both PCR and IgM serologic tests in two patients with panuveitis and only by IgM serologic tests in two patients with acute retinal necrosis (ARN), one of whom had a coinfection with CMV, and CMV caused the primary infection. In two patients with clinically diagnosed VZV-uveitis, laboratory test results revealed dual infection $(E B V+V Z V)$. EBV is considered to infect the ocular pigment epithelial cells [27], but some studies consider EBV as a secondary factor in ocular inflammation rather than as the primary infectious cause $[12,28]$. A few studies have reported that EBV infection might result in ARN; however, this association remains controversial [29]. Therefore, more evidence is required to clarify the role of EBV in uveitis.

For IgM testing, there are two aspects that need to be considered. First, despite low sensitivity, the specificity of IgM test is relatively high, with a low false positive value (sensitivity was 0.151 , specificity was 0.970 , and the negative and positive predictive values were 0.403 and 0.895 , respectively, in our study). Second, as there are endemic areas of viral infection, patients might be broadly positive for IgG; this generalized IgG positivity might not provide any evidence for diagnosis for acute infectious uveitis. For example, more than $90 \%$ of Koreans are positive for anti-CMV IgG [30]. Overall, we think it is clinically significant to compare the diagnostic value of IgM and PCR, as both diagnostic tests have their own distinct role as an adjuvant diagnostic tool in infectious uveitis.
In the real world, clinical features are always important in establishing prompt diagnosis for appropriate management of infectious uveitis, as early detection of the causative pathogen and appropriate antimicrobial therapy are critical in preventing visual impairment from infectious uveitis. Concurrently, detection of viral DNA from either aqueous humor or vitreous is necessary for final confirmation of clinical diagnosis. In cases where the PCR results were negative, but infectious etiology of uveitis is highly suspected, we tried to obtain more diagnostic clue from the serologic testing.

This study had some limitations. First, this was a single-center retrospective study and was limited to a specific patient population that visited a tertiary, referral-based university hospital located in the capital of South Korea. These factors could have introduced potential bias in the study group. To indicate a more representative Korean population for studying infectious epidemiology in uveitis, we recommend additional multicenter large-sample studies. Second, PCR was performed only when an infectious etiology was suspected based on clinical findings of uveitis. This could have underestimated the diagnostic value of PCR. Third, PCR was not performed for all etiologic agents in a patient because of the small volume of aqueous humor samples, laboratory limitations, and financial burden on the patient. Only the most probable viral markers were tested, and this might have further underestimated the diagnostic value of PCR. Finally, a number of patients had unclear diagnosis because of negative PCR and serologic 
test results, and in whom ophthalmic findings were used as the gold-standard method for clinical diagnosis (Table 3).

\section{Conclusions}

Aqueous humor PCR demonstrates a $28 \%$ diagnostic positivity in patients with suspected infectious uveitis. It can be a valuable diagnostic tool for confirming the causative pathogen. In particular, aqueous humor PCR demonstrated good diagnostic value for identifying the infectious etiology of anterior uveitis and panuveitis as compared with that for intermediate and posterior uveitis $(P=0.012)$.

\section{Abbreviations}

ARN: Acute retinal necrosis; CMV: Cytomegalovirus; EBV: Epstein-Barr Virus; ELISA: Enzyme-linked immunosorbent assay; HSV: Herpes simplex virus; GWC: Goldmann-Witmer coefficient; PCR: Polymerase chain reaction; VZV: Varicella-zoster virus

\section{Acknowledgments}

The authors thank Boram Kim (Yonsei University College of Medicine, Seoul, Korea) for help with the study methodology.

\section{Authors' contributions}

Each author took part in the design of the study, contributed to the data collection, participated in writing the manuscript, and all authors accept equal responsibility for the accuracy of the content of the paper. All authors have read and approved the final manuscript. Conception and study design: WC, EYC, MK; data collection: WC, EYC, HGK, MK; data analysis and interpretation: WC, EYC, HGK; drafting the article: WC, MK; critical revision of the article: HJK, SSK, CYK, SCL; final approval of the version to be published: WC, HGK, EYC, SSK, CYK, HJK, SCL, MK.

\section{Funding}

This study was supported by a faculty research grant of Yonsei University College of Medicine 6-2017-0149 and Basic Science Research Program through the National Research Foundation of Korea (NRF-

2019R111A1A01061721). The funding organization had no role in the design of the study and collection, analysis, and interpretation of data, and in writing the manuscript.

\section{Availability of data and materials}

The datasets used and/or analyzed during the current study are available from the corresponding author on reasonable request.

\section{Ethics approval and consent to participate}

All procedures performed in this study were in accordance with the ethical standards of the institutional and national research committee and the 1964 Helsinki Declaration and its later amendments. Approval for this study was obtained from the Gangnam Severance Hospital Institutional Review Board for the retrospective review of existing patient records (IRB number: 3-20170193). Requirement for patient consent was waived by the institutional review board because of the retrospective study design and data anonymization.

\section{Consent for publication}

Not applicable.

\section{Competing interests}

The authors declare that they have no competing interests.
Received: 15 April 2019 Accepted: 12 June 2020

Published online: 19 June 2020

\section{References}

1. London NJ, Rathinam SR, Cunningham ET Jr. The epidemiology of uveitis in developing countries. Int Ophthalmol Clin. 2010;50(2):1-17.

2. Nussenblatt RB. The natural history of uveitis. Int Ophthalmol. 1990;14(5-6): 303-8.

3. Acharya NR, Tham VM, Esterberg E, Borkar DS, Parker JV, Vinoya AC, Uchida A. Incidence and prevalence of uveitis: results from the Pacific ocular inflammation study. JAMA Ophthalmol. 2013;131(11):1405-12.

4. Suhler EB, Lloyd MJ, Choi D, Rosenbaum JT, Austin DF. Incidence and prevalence of uveitis in veterans affairs medical centers of the pacific northwest. Am J Ophthalmol. 2008;146(6):890-896.e898.

5. McCannel CA, Holland GN, Helm CJ, Cornell PJ, Winston JV, Rimmer TG. Causes of uveitis in the general practice of ophthalmology. UCLA Community-based uveitis study group. Am J Ophthalmol. 1996;121(1): 35-46.

6. Westeneng AC, Rothova A, de Boer JH, de Groot-Mijnes JD. Infectious uveitis in immunocompromised patients and the diagnostic value of polymerase chain reaction and Goldmann-Witmer coefficient in aqueous analysis. Am J Ophthalmol. 2007;144(5):781-5.

7. Chee SP, Bacsal K, Jap A, Se-Thoe SY, Cheng CL, Tan BH. Clinical features of cytomegalovirus anterior uveitis in immunocompetent patients. Am J Ophthalmol. 2008;145(5):834-40.

8. Fox GM, Crouse CA, Chuang EL, Pflugfelder SC, Cleary TJ, Nelson SJ, Atherton SS. Detection of herpesvirus DNA in vitreous and aqueous specimens by the polymerase chain reaction. Arch Ophthalmol. 1991;109(2): 266-71.

9. Tran TH, Rozenberg F, Cassoux N, Rao NA, LeHoang P, Bodaghi B. Polymerase chain reaction analysis of aqueous humour samples in necrotising retinitis. Br J Ophthalmol. 2003;87(1):79-83.

10. Matos K, Muccioli C, Belfort Junior R, Rizzo LV. Correlation between clinical diagnosis and PCR analysis of serum, aqueous, and vitreous samples in patients with inflammatory eye disease. Arq Bras Oftalmol. 2007;70(1):109-14.

11. Short GA, Margolis TP, Kuppermann BD, Irvine AR, Martin DF, Chandler D. A polymerase chain reaction-based assay for diagnosing varicella-zoster virus retinitis in patients with acquired immunodeficiency syndrome. Am J Ophthalmol. 1997;123(2):157-64.

12. Sugita S, Shimizu N, Watanabe K, Mizukami M, Morio T, Sugamoto $Y$, Mochizuki M. Use of multiplex PCR and real-time PCR to detect human herpes virus genome in ocular fluids of patients with uveitis. $\mathrm{Br} J$ Ophthalmol. 2008;92(7):928-32

13. Pan J, Kapur M, McCallum R. Noninfectious immune-mediated uveitis and ocular inflammation. Curr Allergy Asthma Rep. 2014;14(1):409.

14. Chung H, Choi DG. Clinical analysis of uveitis. Korean J Ophthalmol. 1989; 3(1):33-7.

15. Lin P. Infectious uveitis. Curr Ophthalmol Rep. 2015;3(3):170-83.

16. Tsirouki T, Dastiridou A, Symeonidis C, Tounakaki O, Brazitikou I, Kalogeropoulos C, Androudi S. A focus on the epidemiology of uveitis. Ocul Immunol Inflamm. 2018;26(1):2-16.

17. Anwar Z, Galor A, Albini TA, Miller D, Perez V, Davis UL. The diagnostic utility of anterior chamber paracentesis with polymerase chain reaction in anterior uveitis. Am J Ophthalmol. 2013;155(5):781-6.

18. Rothova A, de Boer JH, Ten Dam-van Loon NH, Postma G, de Visser L, Zuurveen SJ, Schuller M, Weersink AJ, van Loon AM, de Groot-Mijnes JD. Usefulness of aqueous humor analysis for the diagnosis of posterior uveitis. Ophthalmology. 2008;115(2):306-11.

19. Pathanapitoon K, Kongyai N, Sirirungsi W, de Groot-Mijnes JD, Leechanachai P, Choovuthayakorn J, Kunavisarut P, Rothova A. The diagnostic value of intraocular fluid analysis by polymerase chain reaction in Thai patients with uveitis. Trans R Soc Trop Med Hyg. 2011;105(11):650-4.

20. De Groot-Mijnes JD, Rothova A, Van Loon AM, Schuller M, Ten Dam-Van Loon NH, De Boer JH, Schuurman R, Weersink AJ. Polymerase chain reaction and Goldmann-Witmer coefficient analysis are complimentary for the diagnosis of infectious uveitis. Am J Ophthalmol. 2006;141(2):313-8.

21. Harper TW, Miller D, Schiffman JC, Davis JL. Polymerase chain reaction analysis of aqueous and vitreous specimens in the diagnosis of posterior segment infectious uveitis. Am J Ophthalmol. 2009;147(1):140-147.e142. 
22. Rathinam SR, Namperumalsamy P. Global variation and pattern changes in epidemiology of uveitis. Indian J Ophthalmol. 2007;55(3):173-83.

23. Ronday MJ, Stilma JS, Barbe RF, McElroy WJ, Luyendijk L, Kolk AH, Bakker M, Kijlstra A, Rothova A. Aetiology of uveitis in Sierra Leone, West Africa. Br J Ophthalmol. 1996;80(11):956-61.

24. Wakabayashi T, Morimura Y, Miyamoto Y, Okada AA. Changing patterns of intraocular inflammatory disease in Japan. Ocul Immunol Inflamm. 2003; 11(4):277-86.

25. Mehta S. Pattern of uveitis in a referral eye clinic in North India. Indian J Ophthalmol. 2004;52(4):346 author reply 346-347.

26. Khairallah M, Yahia SB, Ladjimi A, Messaoud R, Zaouali S, Attia S, Jenzeri S, Jelliti B. Pattern of uveitis in a referral centre in Tunisia, North Africa. Eye. 2007;21(1):33-9.

27. Chodosh J, Gan YJ, Sixbey JW. Detection of Epstein-Barr virus genome in ocular tissues. Ophthalmology. 1996;103(4):687-90.

28. Ongkosuwito JV, Van der Lelij A, Bruinenberg M, Wienesen-van Doorn M, Feron EJ, Hoyng CB, de Keizer RJ, Klok AM, Kijlstra A. Increased presence of Epstein-Barr virus DNA in ocular fluid samples from HIV negative immunocompromised patients with uveitis. Br J Ophthalmol. 1998;82(3): 245-51.

29. Oe C, Hiraoka M, Tanaka S, Ohguro H. Acute retinal necrosis associated with Epstein-Barr virus in a patient undergoing immunosuppressive therapy. Case Rep Ophthalmol. 2016;7(1):195-201.

30. Choi SR, Kim K-R, Kim DS, Kang J-M, Kim SJ, Kim JM, Oh SY, Kang C-I, Chung $D R$, Peck KR, et al. Changes in cytomegalovirus Seroprevalence in Korea for 21 years: a single center study. Pediatr Infect Vaccine. 2018;25(3):123-31.

\section{Publisher's Note}

Springer Nature remains neutral with regard to jurisdictional claims in published maps and institutional affiliations.

Ready to submit your research? Choose BMC and benefit from:

- fast, convenient online submission

- thorough peer review by experienced researchers in your field

- rapid publication on acceptance

- support for research data, including large and complex data types

- gold Open Access which fosters wider collaboration and increased citations

- maximum visibility for your research: over $100 \mathrm{M}$ website views per year

At $\mathrm{BMC}$, research is always in progress.

Learn more biomedcentral.com/submissions 